\title{
Trends in National Institutes of Health Funding on the Health-Related Effects of Climate Change and Natural Disasters
}

J Gen Intern Med 37(11):2885-7

DOI: $10.1007 / \mathrm{s} 11606-021-07223-4$

(c) Society of General Internal Medicine 2021

\section{INTRODUCTION}

Climate change represents one of the greatest challenges to humans this century. Heat waves and wildfires in the West, unseasonably cold weather leading to massive infrastructure failure in Texas, and the increasing frequency and destructiveness of hurricanes in the South underline this concerning phenomenon. Its widespread public health impact, particularly on vulnerable individuals, has been acknowledged at the highest levels of the federal government. ${ }^{1,2}$ Moreover, the health-related effects of climate change in general and natural disasters specifically are increasingly recognized, exacerbating risks from wide ranging conditions such as hypertension and depression, to infectious disease risk. ${ }^{3}$ However, scientific evidence to inform mitigation of the health-related effects of climate change and natural disasters is scant.

The National Institutes of Health (NIH) is the largest public funder of research related to health. To understand the current state of public health funding directed towards climate change and natural disasters, we quantify and describe trends in NIH funding by institute/center related to their health-related outcomes over the past 20 years in relation to their entire allocated research funding.

\section{METHODS}

NIH funding for research on climate change and natural disaster-related health effects from fiscal years 2001 to 2020 was ascertained by searching the NIH RePORTER database. We included intramural and extramural research grants denoted as series R, U, P, K, and T funded by any NIH institutes and centers, and excluded funding mechanisms for fellowships, instrumentation, facilities construction, and small businesses (C, F, G, and S series). We searched titles, abstracts, and NIH project terms for the key words "climate change," "natural disaster", as well as "climate hazards", "climate emergencies",

Received August 3, 2021

Accepted October 15, 2021

Published online January 3, 2022 "global warming" or "climate risks". Projects with these terms in either title, abstract, or keywords were extracted. Then, they were described in aggregate and by year according to the source of institute/center funding.

\section{FINDINGS}

Between 2001 and 2020, the NIH funded 1457 climate change or natural disaster research projects, totaling $\$ 576.8 \mathrm{M}$ (unadjusted). Substantial sustained increases in support were awarded after 2009, and starting in 2015, reaching its peak in 2018 at $\$ 72.2 \mathrm{M}$ (Fig. 1). This increase was driven largely by increased funding from the National Institute of Environmental Health Sciences (NIEHS).

Between 2015 and 2020 (Table 1), the largest funder of climate change and natural disaster-related research has been NIEHS with $\$ 219.7 \mathrm{M}$, representing $6.8 \%$ of its allocated research budget during this time. The second largest in total dollar amount was the National Institute of Allergy and Infectious Diseases (NIAID) which provided \$52.6 M in support ( $0.2 \%$ of its research budget), while the third largest was the Fogarty International Center, providing $\$ 25.8 \mathrm{M}$ (5.6\% of its total allocated budget). In terms of total allocated research funds, the remaining seven top institutes/centers provided between 0.1 and $0.5 \%$ of its total budget to climate change and natural disaster-related research.

\section{DISCUSSION}

Climate change and natural disaster research funding has increased over the past 20 years. However, current funding represents a meager portion of overall allocations for NIH's institutes. Nevertheless, developing evidence and building tools to mitigate the public health threat of climate change and natural disasters are stated goals of the Biden administration and the $\mathrm{NIH}^{4}$

Although carefully considered, our findings may be limited by using selected search terms. Nonetheless, the multiplicity of climate change's effects on cardiorespiratory health, depression and anxiety, and the long-term well-being of vulnerable populations (i.e., children, the elderly, those with multiple medical comorbidities, and people of color $)^{5}$ implies the 


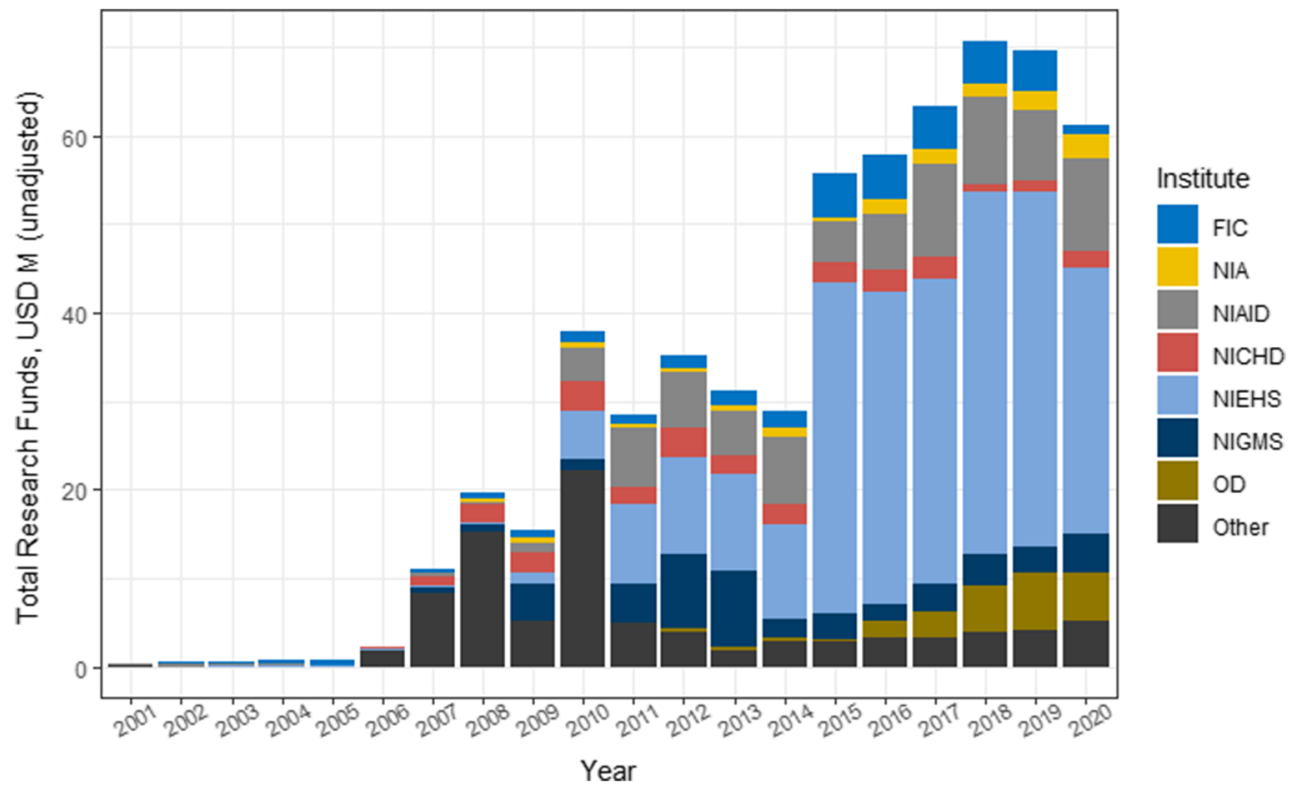

Figure 1 National institutes of health funding related to climate change and natural disasters, 2001 to 2020, by institute, center, and office. FIC, Fogarty International Center; NIA, National Institute of Aging; NIAID, National Institute of Allergy and Infectious Diseases; NICHD, Eunice Kennedy Shriver National Institute of Child Health and Human Development; NIEHS, National Institute of Environmental Health Sciences;

NIGMS, National Institute of General Medical Sciences; OD, Office of the Director; Other, all other NIH institutes and centers combined

burden of funding scientific research should also be borne by other well-funded NIH institutes. Inasmuch as social determinants of health have begun to be incorporated into causal health frameworks, environmental determinants of health should be examined as well. Basic science funding should be commensurate with population-level studies focused on both the attribution of disease-related morbidity and mortality to climate change and natural disasters, and the development and evaluation of evidence-based adaptation and mitigation strategies at local, state, and federal levels, and clinical guidelines for health professionals.

Table 1 Top Ten National Institutes of Health (NIH) Agencies by Funding for Climate Change and Natural Disasters Health-Related Research, 2015-2020

\begin{tabular}{llll}
\hline \hline NIH institutes, center and offices & $\begin{array}{l}\text { Total institute } \\
\text { funding, }{ }^{1} \text { USD } \mathbf{M}\end{array}$ & $\begin{array}{l}\text { Climate change and natural disaster- } \\
\text { related funding, }{ }^{2} \text { USD M }\end{array}$ & $\begin{array}{l}\text { Proportion of institute's } \\
\text { budget, \% }\end{array}$ \\
\hline National Institute of Environmental Health Sciences & 3255.4 & 219.7 & 6.8 \\
National Institute of Allergy and Infectious Diseases & $24,401.1$ & 52.6 & 0.2 \\
Fogarty International Center & 458.9 & 25.8 & 5.6 \\
National Institute of General Medical Sciences & $15,705.3$ & 21.5 & 0.1 \\
Office of the Director & 4514.5 & 21.5 & 0.5 \\
Eunice Kennedy Shriver National Institute of Child & 6919.4 & 11.3 & 0.2 \\
Health and Human Development & & 10.1 & 0.1 \\
National Institute on Aging & $11,487.4$ & 3.7 & $0.1^{*}$ \\
National Institute of Mental Health & 3519.5 & 0.2 \\
National Institute on Minority Health and Health & 1584.2 & 2.1 & $0.1^{*}$ \\
Disparities & $23,913.6$ & \\
National Cancer Institute & & \\
\hline
\end{tabular}

${ }^{I}$ Total institute funding is the total research budget allocated to the NIH institute or center between fiscal years 2015 and 2020

${ }^{2}$ Climate change and natural disaster-related funding is the total climate change or natural disaster related funding between fiscal years 2015 and 2020

${ }^{3}$ Proportion of institute's budget is the proportion of climate change and natural disaster-related funding to its total institute's budget as a percentage *Rounded to the nearest $0.1 \%$ 
The COVID-19 pandemic highlighted the importance of the $\mathrm{NIH}$ and US scientific leadership. NIH funding reflects national priorities to tackle important public health challenges. As the implications of a changing climate become more apparent, the NIH's support should be redirected towards this rising threat.

Arnab K. Ghosh, MD, MSc, $M A^{1}$

Martin F. Shapiro, MD, PhD, MPH

David M. Abramson, $\mathrm{PhD}, \mathrm{MPH}^{2}$

${ }^{1}$ Department of Medicine, Weill Cornell Medical College, Cornell University,

New York, NY, USA

${ }^{2}$ School of Global Public Health, New York University, New York, NY, USA

Corresponding Author: Arnab K. Ghosh, MD, MSc, MA; Department of Medicine, Weill Cornell Medical College, Cornell University, New York, NY, USA (e-mail: akg9010@med.cornell.edu).

\section{Declarations:}

Conflict of Interest: The authors declare that they do not have a conflict of interest.

\section{REFERENCES}

1. Centers for Disease Control and Prevention. Climate Effects on Health. 2021; https://www.cdc.gov/climateandhealth/effects/default.htm. Accessed July 22, 2021.

2. The White House. Executive Order on Protecting Public Health and the Environment and Restoring Science to Tackle the Climate Crisis [press release]. January 22, 2021.

3. McMichael AJ. Globalization, Climate Change, and Human Health. New England Journal of Medicine. 2013;368(14):1335-1343.

4. National Institute for Environmental Health Sciences. Climate Change and Human Health. 2021; https://www.niehs.nih.gov/research/programs/ geh/climatechange/index.cfm. Accessed July 22, 2021.

5. Haines A, Kovats RS, Campbell-Lendrum D, Corvalan C. Climate change and human health: impacts, vulnerability, and mitigation. Lancet. 2006;367(9528):2101-2109.

Publisher's Note: Springer Nature remains neutral with regard to jurisdictional claims in published maps and institutional affiliations. 